\title{
Reflexive Organizing for Knowledge Sharing: An Ethnomethodological Study of Service Technicians
}

\author{
$\operatorname{AUTHOR}(\mathrm{S})$ : \\ Yamauchi, Yutaka
}

\section{CITATION:}

Yamauchi, Yutaka. Reflexive Organizing for Knowledge Sharing: An Ethno methodological Study of Service Technicians. Journal of Management Studies 2015, 52(6): 742-765

\section{ISSUE DATE:}

2015-09

URL:

http://hdl.handle.net/2433/202091

\section{RIGHT:}

This is the accepted version of the following article: YYutaka Yamauchi. Reflexive Organizing for Knowledge Sharing: An Ethnomethodological Study of Service Technicians. Volume52, Issue6, Pages 742-765], which has been published in final form at https://doi.org/10.1111/joms.12136. This article may be used for non-commercial purposes in accordance with Wiley Terms and Conditions for Self-Archiving;; The full-text file will be made open to the public on 06 August 2017 in accordance with publisher's 'Terms and Conditions for Self-Archiving'.: この論文は出版社版でありません。引用の際 には出版社版をご確認ざ利用ください。; This is not the published version. Please cite only the published version. 


\title{
Reflexive Organizing for Knowledge Sharing: An Ethnomethodological Study of Service Technicians
}

\author{
Yutaka Yamauchi \\ Kyoto University Graduate School of Management \\ Yoshida-Honmachi Sakyo-ku \\ Kyoto 606-8501 JAPAN \\ yamauchi@gsm.kyoto-u.ac.jp \\ Phone: +81 75-753-3536
}

\begin{abstract}
WORDS]
This study examines how organizing is done reflexively through practice in the context of knowledge sharing. Organizing concerns reduction of equivocality and sensemaking so that actions can be interpreted and coordinated. Reflexivity refers to the fact that this organizing is done through talk, and that talk is an action that requires organizing. To examine how this reflexive organizing is accomplished, detailed analysis of video-recorded interactions among photocopier service technicians revealed various interactional methods to make actions of requesting and offering assistance understandable and relevant. To explain these methods, Goffman's concept of embedding is applied. By embedding other social situations in the current talk, one can project a certain sense of one's talk. This reflexive organizing clarifies that organizing is part of, not separate from, any practice and that knowledge sharing is accomplished not through a retrospective narrative but through reflexive construction of the situation in which talk is made possible.
\end{abstract}

\section{Keywords}

Reflexive organizing, sensemaking, knowledge sharing, embedding 


\section{INTRODUCTION}

This study examines and explicates how reflexive organizing is accomplished through practice. Practice consists of concrete and embodied actions knowledgeably performed in a particular situation (Miettinen, Samra-Fredericks, and Yanow, 2010; Nicolini, 2012; Schatzki, Knorr-Cetina, and Savigny, 2001), and organizing concerns sensemaking to construct understanding of a particular situation so that actions can be interpreted and coordinated: "people organize to make sense of equivocal inputs and enact this sense back into the world to make that world more orderly" (Weick, Sutcliffe, and Obstfeld, 2005, p. 410). Moreover, in this type of organizing, narratives have been considered central (Czarniawska, 1997; Weick, 1995). That is to say, we make sense of actions by putting together a coherent narrative.

Yet, narratives are not possible in isolation. Telling a narrative is also an action that requires organizing. One cannot simply begin a narrative when others are not prepared to hear it; the situation needs to be organized so that listeners can make sense of this action, telling a narrative, as relevant and legitimate. It is not uncommon that when one speaker attempts a narrative, listeners may not take it seriously (Weick et al., 2005). Therefore, talking is a reflexive part of this organizing. That is, we must examine how organizing is done through talk and at the same time how talk is made possible by that organizing. Prior theories on organizing and narrative have not addressed this question.

This study considers this question in the context of knowledge sharing. Talk has been shown to be key to knowledge sharing. Orr $(1996 ; 2006)$ showed that service technicians often engage in this type of talk in order to construct a coherent narrative and render a problematic situation, i.e., mechanical troubles, sensible. Yet, we need to examine how such talk is possible in the first place. Constructing such a coherent narrative would require possession of the very knowledge that the technicians are seeking, and thus, cannot be pre-supposed. Therefore, this

study seeks to examine how organizing is reflexively produced through talk in order to make the talk itself possible in knowledge sharing. 
Drawing on ethnomethodology discussed in recent studies (Llewellyn and Hindmarsh, 2010a; Llewellyn and Spence, 2009; Nicolini, 2012; Samra-Fredericks and Bargiela-Chiappini, 2008), the current research analyzes photocopier service technicians' practices of knowledge sharing. To this end, interactions among technicians were videotaped, transcribed, and analyzed in detail. This analysis revealed the various methods technicians use to reflexively organize and accomplish the talk of knowledge sharing.

This paper is structured as follows. Firstly, the theoretical framework for the current research is outlined in detail; the concepts of reflexivity and organizing are further clarified. Additionally, Goffman's notion of embedding is reviewed as a key concept in understanding how reflexive organizing is accomplished through talk. Following explanation of the research framework, the subsequent section describes methods and the research site. Specifically, ethnomethodological analysis was conducted on data collected from observation and video recording of service technicians. The Findings section reports various practices of knowledge sharing observed. Discussion follows to clarify reflexive organizing.

\section{REFLEXIVE ORGANIZING}

\section{Organizing as Narration}

Following Weick (1979, p. 44), who proposed to "stamp out nouns," i.e., organizations, and instead to adopt the process perspective with verbs, i.e., organizing, this study chooses to use the notion of organizing as practice as opposed to organizations as fixed entities (Gherardi, 2009; Nicolini, 2012; Orr, 2006; Tsoukas and Chia, 2002). Fixed organization cannot determine actions because situations are not always clear and actions cannot be easily interpreted. Some work, i.e., organizing, is necessary so that participants can both understand and coordinate actions. Organizations such as rules, roles, relations, and tools are enacted through organizing so that they gain a plausible meaning in a particular context. Therefore, organizing is tied to sensemaking; it is about reducing equivocality and making the situation sensible (Weick et al., 2005). 
Organizing is largely done through words: "Organizing itself is embodied in written and spoken texts" (Weick et al., 2005, p. 409). Czarniawska (1997, p. 28) saw, “organizing as narration", indicating narratives are considered as a key process of organizing. Actions are given meaning retrospectively as they are put in a coherent narrative. This is necessary as the ongoing flow of circumstances in organizations is complicated, disconnected, and transitory. Sensemaking through narrative is about connecting disconnected elements within a frame: "stories suggest a causal order for events that originally are perceived as unrelated and akin to a list” (Weick, 1995, p. 129). Particularly, past and present are connected. For instance, we can construct meaning of a current event by pointing out similarities to the past: "Perhaps there is no more common sensemaking gambit than, "that reminds me of a story"” (p. 131), a phrase that essentially indicates a frame from the past is being applied to make sense of a current event.

Narratives are not mere descriptions of actions; they also lead to subsequent actions. The narrative constructs a certain reality (Czarniawska, 1997). Therefore, "The image of sensemaking as activity that talks events and organizations into existence suggests that patterns of organizing are located in the actions and conversations that occur on behalf of the presumed organization and in the texts of those activities that are preserved in social structures" (Weick et al., 2005, p. 413). In other words, organizing constructs a reality through speech and makes coordinated actions possible.

\section{Reflexivity of Organizing}

In the discussion of organizing and sensemaking through narrative, one issue has been largely overlooked. That is to say, the fact that talk is also an action that requires sensemaking has not been much discussed. Weick et al. (2005, p. 412) wrote, "In sensemaking, action and talk are treated as cycles rather than a linear sequence." This characterization may result in misunderstanding; that is to say, it could be construed that talk is not an action, which is not the intent of the theory. We tend to think that talk itself is easily accomplished. In reality, talk is quite problematic. If talk creates a sense of another action, how can the sense of the talk itself be 
created? In fact, the above theory has emphasized that talk is an active effort to enact a reality. This study seeks to clarify this issue and draw attention to the full potential of the theoretical concept of talk as an organizing action.

The notion of narrative emphasizes 'coherence' and 'meaningful wholes' as central aspects of narrative (Garud, Dunbar, and Bartel, 2011; Ibarra and Barbulescu, 2010; Pentland, 1999). Orr (1996, p. 2), described the narrating of technicians as "the creation of a coherent account of the troubled state of the machine from available pieces of unintegrated information." Narrative is organized through a "plot" by which "specific events, otherwise represented as lists or chronicles, are brought into one meaningful whole" (Czarniawska, 1997, p. 18). Yet, coherent and holistic narratives are not possible when we consider talk that is part of the action that it attempts to narrate, as opposed to a separate activity that keeps safe distance from the action. Actual talk is much more complex than post-hoc constructed narratives (Boje, 2001; 2011). Organizing is therefore always unfinished and fragmentary.

Weick (1995, p. 128) stated, "When people punctuate their own living unto stories, they impose a formal coherence on what is otherwise a flowing soup." Similarly, Czarniawska (2008) wrote, "The everyday organizing consists of fragmented activities and events ...But it is just this hodgepodge of events, actions and talks that is the material for the later narratives, for stories that host heroes and villains, dramatic events and daring actions.” Therefore, emphasizing a retrospective coherent whole portrays actual interactions as senseless until retrospective narrating constructs a meaning for them.

In contrast, ethnomethodology emphasizes that actions cannot be taken blindly and that each action is always produced to be understandable; it stresses the reflexivity as one of its core methodological assumptions (Fox, 2008; Garfinkel, 1967; Llewellyn and Hindmarsh, 2010a; Miettinen, Samra-Fredericks, and Yanow, 2010; Nicolini, 2012, p. 137; Rawls, 2008; Tsoukas and Chia, 2002). That is to say that a person's account of an action is itself part of that action. The emphasis on reflexivity highlights that individuals do not act by blindly following rules and procedures. For example, when we shake hands, we do not just abruptly extend our arm; we 
choose a correct timing and keep a proper distance and posture. This allows the individual we are approaching to understand these actions as preparation for a handshake; no other words are necessary. The action of extending the arm is done to make itself understandable as something relevant at that moment. Without this reflexivity the handshake would be problematic to say the least; simply extending an arm would only surprise others.

Scholars do not neglect narratives lacking coherency (Boje, 2011), and conflicts among possible narratives have been pointed out (Czarniawska, 1997, p. 16; Orr, 1996, p. 76; Weick, 1995, p. 136). Czarniawska (2008, p. 33) emphasized "small talk" in everyday organizing. Weick, Sutcliffe, and Obstfeld (2005) placed importance on "the order in organizational life" that comes from "small structures and short moments" (p. 410). Yet, more clarification is needed as to how we can theoretically reconcile these small, conflicting, fragmentary talks and coherent narratives. We propose that sensemaking happens reflexively through small interactions themselves. That is, even without retrospective sensemaking undertaken separately from the action, each action is made sensible within itself.

\section{Reflexive Organizing in Knowledge Sharing}

Knowledge sharing is particularly problematic because any given situation is often unknown, ambiguous, or equivocal. Commonly we might see a person seeking assistance because s/he cannot make sense of the situation, and in this case speaking to somebody for the purpose of seeking assistance is not a simple act. Those who are asked may be busy and/or not see why they need to offer help; they may also think that the problem lies somewhere outside their area of expertise. Furthermore, asking for assistance often reveals one's lack of knowledge, therefore one's incompetence. When we consider all these issues, it seems surprising that we even engage in talk in order to share knowledge.

Technicians in particular often do not have a sufficient understanding of a problem to construct a coherent narrative at the moment it may be needed. Orr (1996, p. 43) described a technician's request for assistance at a lunch meeting. The other technicians at the meeting 
(including one known as Fred) refused the request. "Her task at lunch is to tell this larger story in such a way that Fred will see the parts of it that do not cohere as loose ends to be tucked in, rather than as signs that her account includes disparate elements which do not belong together" (Orr, 1996, p. 43). To accomplish knowledge sharing, technicians need to make their need for assistance sensible even though they may lack sufficient knowledge required for a coherent narrative.

Prior theories on knowledge sharing have therefore discussed various organizational structures, formal and informal, that make such actions possible; informal social networks, strong interpersonal ties, group cohesion, proximity, and trust are all correlated with knowledge sharing (Allen, 1984; Borgatti and Cross, 2003; Cross, 2004; Edmondson, 1999; Hansen, 1999; Reagans and McEvily, 2003; Uzzi and Lancaster, 2003). Yet, such organizational structures do not simply exist to allow the talking. Because the situation of knowledge sharing is particularly unclear, much work is necessary to enact these organizational structures so that participants can make sense of why and how these structures are relevant. That is to say, when we talk, we need to render the talk as a relevant act so that others are compelled to take it seriously. Organizing is done through the very talk that is then made possible by that organizing. However, it remains unclear how this reflexive organizing is done through talk.

\section{Embedding}

This leads to the question of how organizing is reflexively done through talk. To address this issue, we need a theoretical perspective that focuses on social interactions. The following theoretical framework was arrived at through empirical analysis of the data gathered through the current research and is briefly summarized here.

In the current study, Goffman's framework of embedding is utilized. Embedding is a method of organizing at the level of talk. This framework helps explain how we organize while talking. When we talk, we constantly embed other social situations. For example, we may embed another individual's story in our own talking. Embedding thereby connects actions, 
utterances, objects, people, and events from other social situations portrayed by the story to the present practice. This framework also explains how we create sense in a particular situation so that others can find it relevant to offer assistance. Goffman explains that we present a certain 'footing' when we embed other social situations. Footing refers to the fact that when we talk, we always talk as somebody, e.g., an authoritative father, a lively teacher, or a competent technician. This footing shows that we have a warrant for doing what we are doing. The present study focuses on methods of embedding, which are methods of organizing. Therefore, footing is discussed in terms of how it is changed and presented through embedding.

Gherardi and Nicolini (2009, p. 156; 2002, p. 429) similarly wrote, "Through practices of mutual accountability, speaking subjects not only make the world more intelligible but also choose a discursive position for themselves and for others." A similar concept, that of 'positioning', may appear more appropriate than footing (Davies and Harré, 1990). However, I believe that footing is particularly relevant to this study because this concept is tied to the focus of the paper, embedding.

In his explanation of embedding, Goffman (1981) criticized a simplistic view of conversation in which one member of dyad is speaking and the other is hearing. First, Goffman problematized the notion of a speaker. In place of the traditional notion of 'speaker,' Goffman articulates various "production formats," such as an "animator," the one who is producing the sound, an "author," who selects the sentiments that are being expressed, and a "principal," who is involved in the told story (p. 144). Embedding alters the production format and thereby the footing. For instance, by embedding another individual's story in our own speech, we present our footing as that of an animator only, distancing ourselves from being the author or principle of the story. Clayman (1993) showed that news-interviewers can present themselves as neutral by citing another person's opinion rather than by expressing their own view. Orr (1996) briefly touched on production format when he described the use of first-person ("I") and second-person ("you") that technicians alter when telling stories. Use of the first person indicates "the 
awareness of situated experience that gives credibility to the more general accounts," which were told in the second-person (p. 133).

Goffman (1981) similarly criticized the narrow view that speech is generated toward a simple 'hearer', and proposed as an alternative the more inclusive concept of a "participation framework" (Goffman, 1981, p. 137). The participation framework includes not only the people engaged directly in listening to the speech, but also all others who could be indirectly hearing the speech. A variety of social situations can be tacitly embedded through a participation framework. Actual interactions demonstrably encompass a larger participation structure involving more people than the two primary interlocutors. "Bystanders," who are not official participants, are consequential to the interaction because they can "overhear" or "eavesdrop on" the conversation (p. 132). Similarly, Gherardi (2009, pp. 155-156) described how people introduced "a virtual participant," or "a dummy participant" (p. 87) to advance their position in a debate (see also, Gherardi and Nicolini, 2002). Therefore, when we talk, we are faced with multiple situations that can be embedded, e.g., not only that of the hearer but also of others who may be aware of the conversation.

Through this type of embedding in both speaking and hearing, talking presents a certain footing on which the speech presents itself and projects a certain sense of the situation. It is important to note that when we embed other social situations, we do not explicitly describe them; there are many subtle ways of embedding. The current research seeks to clarify how reflexive organizing is accomplished in the context of knowledge sharing through examination of this type of embedding.

\section{METHOD}

\section{Research Setting}

This study examined service technicians at a large U.S. office equipment manufacturer. The technicians needed to share knowledge constantly in order to fix technical problems with photocopiers. Orr (1996) also described this type of work by technicians, however the data for 
the present study were collected in 2001 and 2002, some time after Orr's study. Nonetheless, the troubleshooting practices that Orr describes have not changed to any great degree, although sophisticated diagnostic tools have been introduced and advances in digital and network technology have resulted in highly complex machinery. The technicians observed for this study used a radio system that enabled them to talk with their colleagues instantly and to multiple people, e.g., their workgroup, simultaneously. Orr was responsible for introducing this radio system and making the technology successful (Orr, 1995). The technicians also use laptop computers with various specialized applications, most of which were diagnostic tools designed to interact with the photocopiers.

The technicians were organized into workgroups according to the products on which they worked. There were roughly three product categories: (a) high-volume black-and-white products, (b) mid-volume black-and-white products, and (c) color products. Each workgroup serviced one category of product within a geographical area. Specialists who had been promoted from positions as technicians helped current technicians with difficult cases, and the specialists were also the first to be trained to repair new products and receive technical information.

The technicians' work was organized around service calls placed by customers to a support center. Each service call was documented and assigned to a technician responsible for the machine. The technicians checked, responded to, and documented service calls with callhandling software installed on their laptops; they checked the call queue frequently and responded to calls in the order of urgency. Additionally, they checked the queue every morning at a parts drop, a field station where they ordered and picked up parts. During their shift, technicians either returned to the parts drop or used a phone line at a customer site to connect their laptops. After solving a problem, they responded to another service call.

To commence the present research I held a meeting with eight field managers who directly supervised the technicians; I explained the purpose of the study, and then the managers selected several technicians to participate in the study. The managers explained to the selected technicians that I was going to conduct an independent study and that the collected data would 
not be shared with management or used for evaluation purposes. Thereafter, I met a group of specialists who worked with the selected technicians, and these technical specialists detailed the content of the daily work done by the technicians. A summary of the study participants is presented in Table I. As the table shows, four product specializations were examined: high, mid, color, and general. The last category refers to generalist, a specialization often held by technicians in rural areas who work on multiple product categories.

\section{INSERT Table I ABOUT HERE}

I followed 16 technicians over a four-month period to collect data, accompanying them on field rides in their vans, which typically started at 8 a.m. and continued until 4 p.m. During business days, I spent the entire observation time with the technicians, eating lunch with them and also joining informal work events such as barbeques. The total observation time amounted to about 106 hours. Whenever possible, video and audio recordings were made as the technicians worked on machines and talked to other technicians and customers. For each service call, I started recording as soon as technicians began troubleshooting and continued until the work was completed and the technicians were ready to leave the site. I also videotaped the technicians when they were at the parts drop. Before going to a customer site, the technicians were always asked what they knew about the problem they had been assigned. Most troubleshooting was done alone and was difficult to understand; therefore I asked the technicians to verbalize their thought processes. If they forgot to verbalize these processes, whenever possible, I asked them about the work they had conducted and what conclusions they had reached. At the end of a service call, the technicians detailed the troubleshooting process from beginning to end. Subsequently, after following these workers through their daily schedules, I conducted retrospective interviews with the participants by phone or email to clarify details that had been noted in the videos. 


\section{Conversation Analysis}

The current study uses the method of conversation analysis, a sociological approach derived from ethnomethodology. Scholars have pointed out that ethnomethodology and conversation analysis have much to offer organizational research (Fox, 2008; Llewellyn and Hindmarsh, 2010a; Rawls, 2008; Samra-Fredericks and Bargiela-Chiappini, 2008). This approach employs audio and video recordings, allowing the researcher detailed access to the settings. While there are other forms of ethnomethodology, e.g., ethnography, Llewellyn and Hindmarsh's (2010a) description of their use of audio and video recording clearly demonstrates the benefits of this methodology: "drawing on audio/video recordings from a diverse range of work domains, these authors both explicate the local organising properties inherent to organisational conduct and consider the relevance of these properties for (re-)understanding core concepts in organisational literatures" (Llewellyn and Hindmarsh, 2010b, p. 5).

I analyzed about 48 hours of video; I first created a log for each service call indicating what activity technicians were doing, e.g., reading machine logs, reproducing a problem, or replacing parts. As the daily activities of the technicians were understandable through this log, I focused on interactions of any sort that happened, including interactions with a customer. The interactional data were transcribed using the standard transcription format described by Sacks et al. (1974), as shown in the Appendix. A detailed sequential analysis was made for each the interactions. At this time, the analyses were quite disparate - for instance, there was no apparent commonality between quick questions and talking aloud. Subsequently, as the analysis gradually revealed an overarching theme, i.e., embedding, I grouped the various patterns of embedding. The overarching theme helped me see the disparate patterns as variations of the same interactional structure. The data will be presented according to these patterns below.

The sequential analysis examines practices on a moment-by-moment basis. This analysis focuses on sequential organization of unfolding actions and interactions. Sequential organization "refers to the idea that the sense of a turn at talk in conversation, or indeed any 
action in interaction, arises form its positioning with respect to an immediate before and after" (Hindmarsh and Llewellyn, 2010, p. 26). To understand the sequence of actions, the question "Why that now?" was asked for each turn (Schegloff, 2007, p. 2). For whatever was said or done, the meaning of a particular utterance or action was explained in terms of its position in the sequence in relation to any other actions that had been taken. Because participants themselves display their understanding of prior actions to other participants, researchers should ground their analysis on this understanding rather than imposing their own understandings.

For instance, when I observed one technician speaking to another, I examined the meaning that this speech presented through its position in a sequence consisting of prior actions. Utterances were not simply undertaken without context; for instance, when a technician was speaking, he or she was utilizing elements of previous actions and conversation, so that others could understand the meaning of this speaking in light of these prior actions. Analysis of the meaning of an action was then confirmed in the manner that others exhibited their own understanding of the action by means of their responses to it, e.g., treating the action as part of the prior context rather than something new. Through this sequential analysis, I was able to describe the meaning of an action as presented and understood by the participants in an interaction without imposing my own interpretation.

Throughout the fieldwork I asked many questions and collected records of a number of documents, e.g., machine logs, computer screens, cheat-sheets, and work manuals. In the following analysis, I include these data as background for analyzing actual interactions among technicians. Ethnomethodology seeks to explicate the understanding that members themselves exhibit through their actions; thus it must focus on information that members themselves are oriented to within an interaction. Any information that was not available to the participants at that moment was not used. On the other hand, because members shared some background knowledge that was not necessarily discussed or observed in the video recordings, I needed to acquire this information by asking questions, and I used the information as background data for understanding how participants were oriented to their actions within the interactions. Therefore, 
analysis is explicated within the sequence of an interaction, and other data such documents and interviews are used as background information.

As I spent an extended amount of time in the field with technicians, my own experience was important for the analysis. Because my experience was not something members were oriented to in their interaction, I could not incorporate it directly in the analysis. Nonetheless, my experience guided the analysis with respect to which data was of particular relevance. For instance, I had difficult time speaking to technicians when they were visually concentrating on a task. In order to ask a question, I sometimes used several tactics such as quietly moving myself in their field of vision to catch their attention and inhaling audibly to make my presence salient. Gradually I learned that talking required a context to make speech relevant and that there were ways to construct the context.

\section{FINDINGS}

\section{Explicit Inquiries}

I begin with cases where technicians explicitly approached one another and asked for help. When they did not know exactly what to ask for, they could not easily ask a specific question but needed to describe the problem in many words. First, I will show that explicit inquiries were possible only with proper organizing. During the research, not many instances of explicit inquiries were observed: Interrupting others and asking a lengthy question is not easy. Second, I will describe embedding through which other social situations are brought to bear in order to construct sense in longer inquiries. All technician and specialist names in the following sections are pseudonyms.

In the first situation, Terry, a color-machine technician with 17 years' experience, was working on a problem to which he had been assigned when Tucker contacted him by radio. Tucker started by asking, "Hey Terry, can I ask you a question uh::." This upfront question made Tucker's reliance on Terry explicit. He then described the problem he was working on. The customer was using paper stock not supported by the company, and dust from this paper 
caused deletion — some parts of images were not printed clearly. The customer received the proper paper that day but the deletion problem persisted. Tucker then came to his question, "Do you know if there's anything N- NVM that changes that you can do: or help us (do)."NVM (non-volatile memory) is a kind of memory used in the machine. Saying, "No:, there is no NVM set up," Terry told Tucker to replace the developer. Tucker revealed that he had replaced the developer three days before. Terry insisted that Tucker needed to replace the developer once again.

In this example, Tucker issued a lengthy description of his problem; his request was 38 seconds long. Tucker had to give the context of what he had done up to that point in order to ask a specific question. It was not readily apparent that Terry was available to help except for the brief acknowledgement, "Go ahead." In the data, this type of explicit asking was not common. When he finished speaking on the radio, Terry said to me, "I trained Tucker in the field." New members usually ride with experienced technicians after classroom training so they can learn how work is done in the field. Terry did not need to ask Tucker which product was being referenced. The social situation of trainer-trainee relationship was embedded so that Tucker projected a footing as a trainee, which allowed Terry to immediately make the situation sensible.

Even with this footing, Tucker could not simply ask the question about the NVM setting without justification. The specific question that Tucker wanted to ask about NVM was in fact a sensitive question. He was seeking some workaround with the NVM setting so that the customer could continue to use the developer, which he had replaced only three days earlier. Terry reiterated that Tucker should follow the procedure and tell the customer to replace the developer again. He said that in this type of situation, even over a period of three days the developer could be contaminated. It was not easy to ask the customer to pay for this part once again. As Orr (1996) showed, technicians need to manage customers as well as service machines. Thus here, not upsetting the customer is a good justification: The embedding of a customer induces the footing of a technician with a justified motivation. 
In another example, Taylor ran into a colleague, Teagan, at a customer site. They chatted while Taylor worked on a color machine, replacing a fuser module. Taylor then spoke to Teagan, "How much time you got, Teagan?" is a typical pre-request or pre-offer (Schegloff, 2007, pp. 34-35), which is not heard as a literal question but as a hint for a request or offer that might come. Answering this type of question is not simple if one does not know the nature of the possible request or offer. Teagan responded, “Uh, I'm waiting for [the specialist] to fix this machine." Teagan was vague and noncommittal, careful not to expose herself to Taylor's agenda. Taylor continued, "Because this is one of the things that you would be interested in learning more about. This fuser." This prompt explanation about the fuser clarified Taylor's agenda, and she then started to explain how the fuser module was assembled.

Teaching a colleague is a sensitive issue because teaching implies a certain imbalance of knowledge. In this particular case Taylor, as she explained to me later, was the only one in her workgroup who had been trained on color products. She was responsible for teaching others about this product category. The social situation of official training was relevant in that Taylor could make her teaching sensible, and Teagan's lack of knowledge did not imply a deficiency on her part. Taylor removed herself in her explanation, e.g., not saying "I can show you how...," and instead suggested that Teagan "would be interested in learning."

\section{Quick Questions}

The technicians used short questions as well as lengthy, explicit inquiries. Quick questions are effective in launching the conversation, incurring the least interruption (Pentland, 1992). However, the present study sought to determine the method by which a quick question was possible through embedding. The difference between these quick questions and the explicit questions was a shared understanding of the nature of a problem. To issue a quick question, the person being asked needed to know the specifics of the request. For instance, a technician who had previously worked on a similar problem with another technician could easily initiate a 
conversation with this other technician. In such cases, by embedding the past situation, the technician made the quick question sensible.

We can see this type of interaction when, Spence, a specialist, had fixed a problem with printer controller software but still had to install a device driver software for a video board because the graphics on the controller monitor had been reduced to a lower color depth. Since he had no installation CD, Spence needed to radio another technician, Troy. In this case, he opened with a quick question: "Troy, it's Spence. Do you have the, uh, driver for the advanced video board?" This question at first appears to be too brief. There was no explanation of the present context, nor was there any pre-request such as "Have you got a second?" Spence indicated "the" specific advanced video board and radioed Troy because he had previously worked with Troy to fix an identical problem. Therefore, Troy knew why he was being asked. Troy did not need to ask which product the driver was for; Spence understood that Troy would understand the interaction without explanation because of their shared history with similar problems.

In another case, Tom radioed a specialist when he was unable to solve a problem. His initial utterance (after "Do you copy?") was, "I am working on X12. Which board is the personality board?" In the X12 product, the personality board is a hardware board inserted into the printer controller. This question is too elliptical to be intelligible without some shared context; that is, unless Tom understood that the specialist knew the personality board. After the specialist provided an answer, Tom continued, saying, "It actually says I can power on without the personality board." The word "it" here refers to the repair instruction. After this initial exchange, they resolved the problem together through a longer discussion. Tom had worked with Spence earlier on a similar hardware problem, providing a reason for Tom's short, precise question.

Here we can see that quick questions required embedding of a past situation. In other words, although quick questions were efficient, they were not possible out of context and required that past situations be embedded to make them sensible. These questions were far from 
narrative in that they were terse and fragmentary (Boje, 1991; 2001). Nonetheless, they presented an account so that they were acceptable and understandable.

\section{Negotiating for Help}

So far we have seen cases where technicians asked questions and anticipated verbal assistance. However, when technicians requested that somebody come to a current location and offer assistance, a more thorough justification was needed. An individual asked for this type of help might challenge the grounds on which the request is made and refuse to help. Technicians at times may ask a specialist to travel to a site in order to solve a problem together. These experts, and their time, are scarce resources. Although they are typically willing to help others over the radio, they cannot spend time with all the technicians who approach them because more important problems might need attention. Therefore, specialists must optimize the allocation of their time.

Terry, previously mentioned in the discussion of explicit inquiries, encountered a problem requiring this type of assistance. Terry radioed a specialist named Spence. After lengthy exchange, Spence came to the conclusion that there was a problem with the network configuration: "Yeah, something to do with configuration, you know." Then, he asked Terry about software installation disks (in the following, one point one and one point five are versions of software, and the driver is software that controls a hardware board). Spence said, "Do you have that one point one software?" Terry replied he did, and then Spence also asked, "Do you ha:ve the uh advanced uh video board (.) driver?” Terry responded negatively. After further discussion, Terry said, “I don't wanna go over there at- I don't have one point five. They never sent it (.) to me. (1.4) For the Fiery? But I got one point one?” Immediately, Spence said, “” Okay ${ }^{\circ}$ Well (0.9) U:m: ${ }^{\circ}$ What time is it? ${ }^{\circ}$ I'll give you a call in about an hour. Do what you can do. ( ) I got to hold this software."

By saying, "I don't have one point five," Terry was trying to make use of the fact that he lacked the necessary software. That is to say, he embedded this object and lack thereof to 
solidify his justification for assistance-it was not his incompetence but the tool he lacked that was problematic. By saying, "They never sent it to me," he was directing blame to "them" and away from his competence. Here, "they" is heard to be people at headquarters who were embedded here to project the footing of Terry's blamelessness. His "For the Fiery? But I got one point one?" is heard to imply that he was fully equipped to do his work but not this particular software. Immediately thereafter, Spence agreed to continue the discussion. All these embedded tools and people created a complex web projecting the specific footing of an individual in need of assistance but not responsible for the failure to solve a problem.

Later, Terry radioed Spence again. Over the radio, Spence had Terry check the network interface card (NIC) setting on the Fiery and the IP and subnet addresses on the configuration sheet $-\mathrm{a}$ sheet of paper listing all configurations. Terry reported that the light on the network card was on. Therefore, Spence concluded that there was problem with the configuration. Terry is indicated as Terr and Spence as Spe.

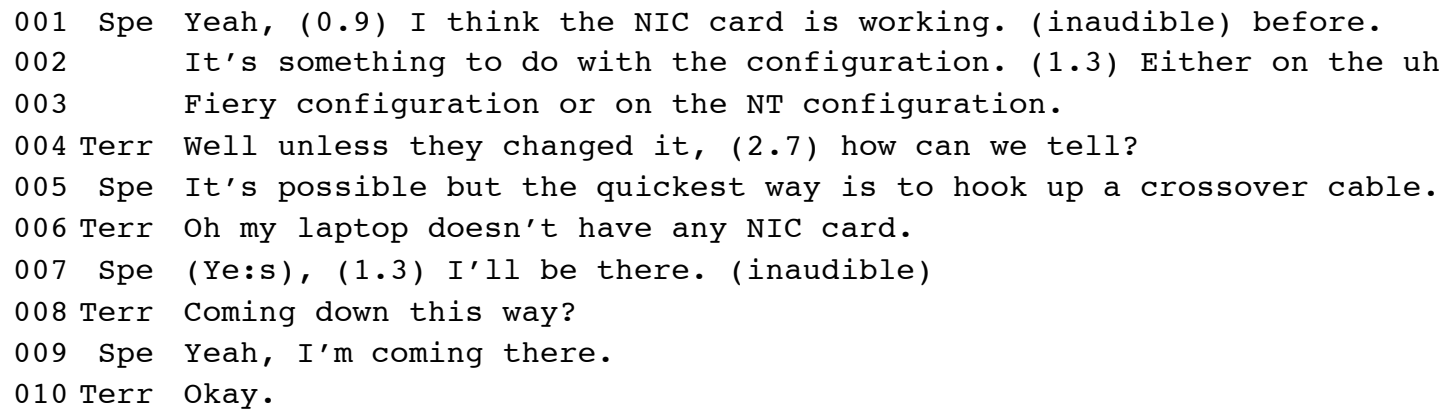

Finally, Spence determined the problem was sufficiently critical that he should come and help. The fact that Terry did not have the necessary tools (i.e., the network card and the crossover cable) compelled Spence to agree to assist in resolving the problem. The remark "Oh my laptop doesn't have any NIC card" in line 006 is similar to the previous remark, "I don't have one point five. They never sent it to me." Note that Spence agreed to come and help immediately after this remark. From the beginning, Terry had claimed that the problem was more complex than simply a wrong setting, such as a wrong IP address. Two long conversations were necessary to defend his claim. 
In these examples, embedding was made explicitly. An overt request for assistance was made at the beginning of the conversation, but this required negotiation in which various other social situations are embedded. Both Terry and Spence recited stories of various other social situations. What made this knowledge sharing possible was not Terry's logical and technical explanation of the problem but his organizing, which embedded such heterogeneous elements as tools, persons at headquarters, and other technicians.

This kind of explicit embedding was needed in another situation when a technician offered a colleague assistance: A less-experienced technician, Theo, suggested a solution to a problem on which Tom, a much more experienced technician, had worked in vain for nearly an hour. When Theo saw Tom's problem, he quickly proposed a solution. After demonstrating the solution, Theo repeatedly emphasized that he had run into the same problem a week prior-a fact he repeated at least five times. Theo's attribution of his knowledge to the luck of having encountered the same problem before and not to his competence relative to Tom helped his more experienced colleague save face.

\section{Situated Asking and Helping}

More nuanced practices were observed when technicians did not initiate help seeking explicitly, as situated asking is contextualized in an ongoing activity. This pattern took the following form. One employee opportunistically observes an ongoing activity of another, embedding him or herself as a bystander overhearing the ongoing conversation, and embeds asking in that ongoing activity. The following scene occurred earlier on the day that Terry, before going to the site, radioed Spence to ask for assistance at the parts drop. As Terry was about to conclude the radio conversation, another technician Tyson, denoted as "Tyso," was working on his laptop. Photographs are edited to make the people unidentifiable. 
The conversation between Terry and Spence continues.

\begin{tabular}{|c|c|c|c|}
\hline 101 & Spe & $\begin{array}{l}\text { That's why you can't do it. Must be wrong } \\
\text { number. }\end{array}$ & 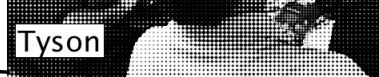 \\
\hline 02 & Terr & I'm hoping. Okay. ((Hands up the radio)) & \\
\hline 103 & & $(1.0)$ & \\
\hline 104 & Tyso & What did he say? $(0.6)$ It means what? & Spe \\
\hline 105 & & $(0.7)$ & \\
\hline 106 & Terr & IP address is messed up somewhere. & \\
\hline 107 & & $(1.1)$ & \\
\hline 108 & Tyso & $\begin{array}{l}\text { O:nce we ping- Tevin even put his laptop to it } \\
\text { with the hu:b so, }{ }^{\circ} \text { we just had it (for) }{ }^{\circ} \text {. Put } \\
\text { his laptop with the hub that o we couldn't } \\
\text { ping }{ }^{\circ} \text {. It- it answered once. }\end{array}$ & \\
\hline 109 & & $(4.6)$ & \\
\hline 110 & Tyso & You know how [we & \\
\hline 111 & Terr & [I talked to $\mathrm{u}: \mathrm{m}$ what's his name?, & Tyson looks at Terry. \\
\hline 112 & & $(0.6)$ & \\
\hline 113 & Tyso & Talon? & \\
\hline 114 & Terr & $\begin{array}{l}\text { Andy? He's now the uh: (post)? }(2.0) \text { does the } \\
\text { low-end color. }\end{array}$ & \\
\hline 15 & Tyso & Uh huh & \\
\hline 116 & Terr & $\begin{array}{l}\text { He's like the analyst of the DC products? } \\
(1.2) \text { And he said if there is a problem with } \\
\text { (the) network, ( ). I was gonna go over }\end{array}$ & \\
\hline
\end{tabular}

117 Tyso Alright. Good luck.

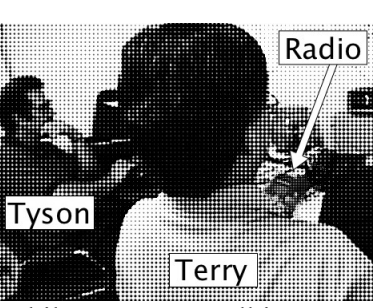
was facing his laptop.

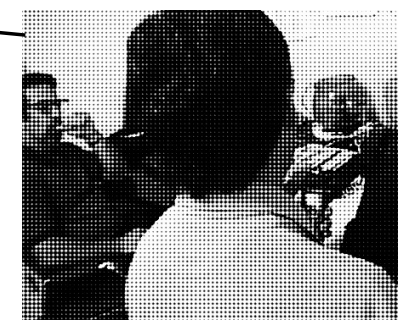

Terry stands up.

As soon as Terry ended his radio call, Tyson, sitting next to Terry, spoke to him (line 104). Tyson overheard Terry's radio conversation with Spence while he himself was talking with somebody else; this overhearing was embedded in these two activities. It should be noted that Terry's radio was set to speaker mode. By situating his question within Terry's course of action, Tyson was able seamlessly integrate his question into Terry's situation. Tyson used the deictic terms "he" and "it" in line 104, indicating that his interaction was already embedded in the ongoing interaction in which these deictic terms could be rightly determined; therefore, two different practices were connected into a single practice.

Although Tyson was adept in initiating the interaction, Terry did not necessarily welcome it - he did not accept the invitation to an extended conversation. Terry switched the topic to the fact that Andy might be able to help (lines 110-114). By standing up in the middle of the discussion, he implicitly indicated that he was ready to leave the conversation, embedding his next action of leaving the parts drop, and presented a footing demonstrating that he was on the 
move. Tyson's responses became more cursory. During this brief exchange, however, Terry actually gained one piece of information: the 'ping' only worked once. He recalled and reported this information when he later talked to Spence.

In another case, the same method of observing another person and situating a sequence into another's activity was used in an interaction of an offer to help rather than seek help. While Tom was finishing a service call, Terrence arrived at the site for another call. Tom was at the time discussing new calls with his workgroup on the radio. While still engaged in the discussion, Tom suddenly addressed Terrence, who was working on a machine behind Tom's. Terrence is

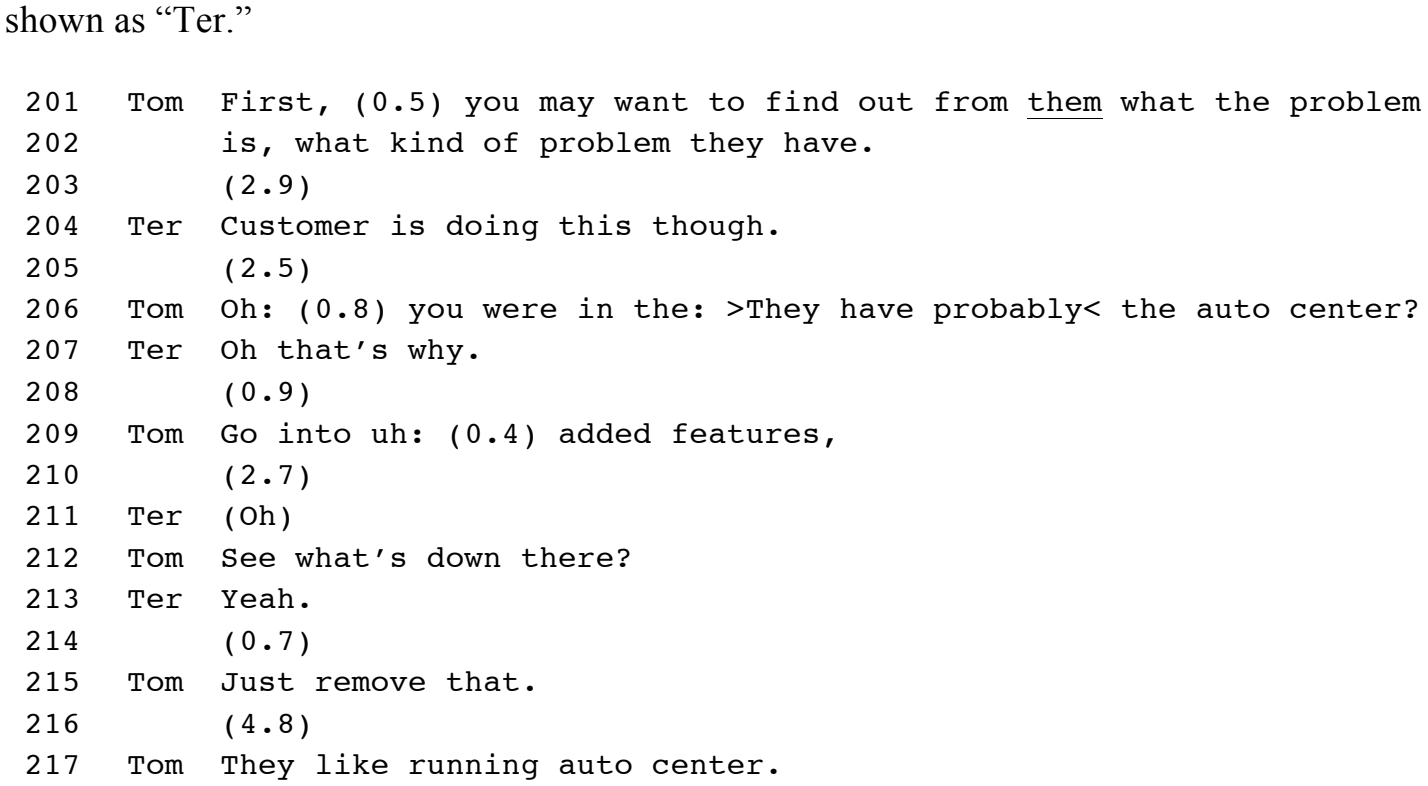

The term "auto center" (line 206) refers to a machine feature. After this sequence, Tom demonstrated how to change the setting, and Terrence was able to start troubleshooting. Tom was attentive to Terrence's difficulties, but Terrence did not ask for help while Tom, a more experienced technician, was talking on the radio. Although Tom observed Terrence, he did not necessarily have a clear suggestion to offer; he only sensed that Terrence was having a problem with a machine that prohibited him from being able to begin troubleshooting. Terrence's response, "Customer is doing this, though" (line 204), was sufficient for Tom to understand the problem, although this utterance had little information and was centered around a deictic "this." As Tom said in line 206, he knew this was a typical problem; he was familiar with this 
particular company because it was actually his usual customer. Therefore, it was apparent Tom had knowledge that Terrence lacked.

Situated asking and helping exhibited subtle embedding. In this case, one monitored and overheard another's social situation and then embedded one's action into that situation. The monitoring and overhearing of another activity in which one is not explicitly involved indicates a subtle participation framework, i.e., that of bystanders (Goffman, 1981). Because the asking and offering was situated in the others' social situation, it was immediately made sensible; it was clear why one is being asked or help is being offered.

\section{Talking Aloud}

Technicians also indirectly made their problems visible, enabling others to see the problems and offer help. Here, there is no directly apparent "asking." In a later phase of Terry's service call, he used some free time to check new calls on his laptop. A call came in for which the assigned technician was on vacation, so anybody not engaged in a current task was supposed to take this call. Terry then radioed his workgroup to let them know about this new call. Another technician, Tyler, says, "I will pick that up in a couple of minutes." That is to say, Tyler would be done with his own call and be ready to take this new call. "Okay Tyler, thanks," responded Terry. Then, after 1.4 second pause, he added, "I'm waiting for Spence to show up." To this, Tyler responds, “That wasn't the IP address then, huh?” In the subsequent conversation Tyler then taught Terry a troubleshooting technique to try.

Terry's utterance, "I'm waiting for Spence to show up," was not necessary for the conversational organization because his words "Okay Tyler, thanks" comprise a typical closing utterance. He most likely said this as an excuse for not taking the service call himself. There was a reason why he did not say, "I am busy with a difficult problem"; he had the time to check the service calls by connecting his laptop to the network and was apparently not busy in that sense. Therefore, he had to give an account for why he was not busy but was unable to help the team by taking the service call. Waiting for a specialist is a good excuse because it is readily 
apparent that his problem was sufficiently difficult to require specialist. Moreover, since a specialist was needed, all Terry could do was to wait for this specialist to arrive. This is another example of embedding another individual who is not seemingly relevant in order to avoid blame or offer a good excuse.

In this case, another technician, Tyler, responded. Terry's utterance was designed to reveal his problem indirectly. Therefore, Tyler did not have to respond to this utterance if he was busy with his own work. In this case, Terry had discussed the problem with Tyler earlier that morning. Yet, Tyler knew only the general characteristics of the problem (i.e., the network problem). This utterance established that the problem was deeper in the network. Tyler then showed Terry new troubleshooting technique.

In a similar case, Trinity made a problem visible in a face-to-face conversation. Trinity and Toby had been chatting about their performance evaluations. When Toby started to leave, Trinity spoke to herself in a louder voice (line 306). Toby returned and responded. Trinity is shown as "Trin."

Trinity and Toby have been talking about performance review.

301 Toby I can show you mine probably ${ }^{\circ}$ the same ${ }^{\circ}$. $302 \quad(0.5)$

303 Trin ${ }^{\circ} \mathrm{No}^{\circ}=$

304 Toby = Probably changed some (things).

$305 \quad$ (3.2)

306 Trin Alright h try this again.

$307 \quad \overline{(1.0)}$

308 Toby What's going on?

$309 \quad(1.4)$

310 Trin Uh:: I just (.) took it down, because

311 it had that o three four (.) eighty,

$312 \quad(3.0)$

313 Trin A:ll the way do: : wn.

$314 \quad(0.8)$

315 Toby You were in diagnostics?

$316 \quad(1.7)$

317 Trin Ya.

$318 \quad(1.8)$

319 Toby Huh.

$320 \quad(13)$

321 Trin what happened to number three?,

Trinity's utterance, “Alright $\mathrm{h}$ try this again" (line 306), was directed to herself-selftalk — because she was going to try to work on her problem again, yet she clearly made it in a 
brighter voice, in stark contrast to the previous "No." She did not have to utter this self-talk in a louder volume unless it was to be directed at Toby. When she spoke, Toby had already turned away from her, and this utterance captured Toby's attention. In Goffman's (1981) terms, the bystander was embedded, and Trinity took the footing of a person innocuously revealing her problem without the intention to seek assistance. The first short "Alright" prepared Toby for her subsequent utterance. The word "again" was crucial in telling Toby that Trinity had tried something in vain, and the exhale, "h," conveyed fatigue or irritation. Toby's reply, "What's going on?" (line 308), reflects this point because something was "going on." In this short, ambiguous utterance, the situation of repeated failure to solve the problem was embedded.

Toby did not reply to Trinity's explanation of the problem for 3.0 seconds (line 312), a rather long time. Typically, when an answer is given to a question, the person who asked the question is expected to assess the answer. Upon the lack of such an assessment, Trinity added another utterance jokingly. Then Toby managed to ask, "You were in diagnostics?" In addition to its literal meaning, this question is audible as an invitation for Trinity to provide more details so that they might be able to work on the problem together. At this moment, the long pause clarified that Toby had no concrete advice. Trinity's short answer, "Ya," shut down further knowledge sharing. Although this interaction did not result in assistance, much work was involved in discovering whether Toby had any useful information and concluding the interaction smoothly. Trinity initiated the interaction without knowing whether Toby could help. Through the implicit interaction, Toby's lack of knowledge was not necessarily made explicit.

In the above conversations, the technicians embedded subtle participation frameworks and connected others' activities to theirs; they did not even ask for assistance and therefore did not need explicit justification. They revealed their problem but presented it as unproblematic and benign. Even when others were not willing to offer assistance, no problem would arise. This was all possible because of the embedded participation framework. Self-talk and indirect utterances were embedded in the ongoing interaction. 


\section{Summary of Findings}

The above findings can be summarized in terms of two phases in the interactions. First, organizing is needed to initiate the actions of seeking and offering assistance; the question for the participants is why this particular action is taken at this moment. It is important to choose a particular timing and a particular individual and then to formulate asking in a sensible way. In prior studies, this first phase has been largely overlooked: Talk has been treated as already initiated. This study revealed that talk is problematic and that organizing is needed for initiating an interaction. In the second phase, even with this type of organizing in the first phase, others often cannot simply accept the situation and begin offering or receiving assistance. They may challenge the claim that assistance is relevant. Further negotiation is required to make the action sensible.

Regarding the first phase, we observed two ways to conduct organizing. First, when one person approached another and asked a question, whether this inquiry be either quick or explicit, the person initiating this interaction embedded another social situation to create sense in the act of asking. The official roles such as trainer and specialist and the official process of training were embedded to show that one had legitimate footing to approach others. Past situations were also embedded to show the footing related to this past situation continued into the current situation and to construct short but understandable questions. By embedding these other social situations, technicians used varied production formats and presented varied footings. These footings were helpful in rendering the situation of knowledge sharing as sensible so that others can see the relevance of the particular knowledge sharing attempts.

The second way organizing was conducted in the first phase was to embed other social situations happening at the moment. Thus, the examples in the current study point out that multiple current situations at a given moment are embedded in each other and accordingly a new situation is initiated. Here, various participation frameworks are embedded in the focal interaction. This involves a preparatory sequence in which one monitors others before initiating 
an action. Through this monitoring, one's action is embedded into the situation of others, often with deictic terms, so that it could be immediately made sensible. Alternatively, a person makes his or her action visible in an indirect way so that others can respond to it. One short utterance, which may be ambiguous but projects important information, often paves the way. No question or request was necessary.

The second phase involved explicit sensemaking through embedding other social situations such as other technicians, tools and parts, customers, past events, and organizational structure. In one case, a specialist and trainer challenged an initial request for assistance and the technicians needed to project a more acceptable footing through embedding. This was also observed when a less experienced technician assisted a more experienced one. The former needed to show repeatedly that it was not his expertise but rather his luck in having previously encountered an identical problem. Here, we can see that technicians explicitly and indirectly cite stories from the past and from other people using various production formats.

\section{DISCUSSION}

\section{Reflexive Organizing through Embedding}

Many theorists have shown that organizations need to be enacted in practice and therefore organizing as a verb is preferred to organization as a noun (Bittner, 1965; Gherardi, 2009; Nicolini, 2012; Orr, 2006; Tsoukas and Chia, 2002). Fixed organizations do not make practices possible because situations are equivocal but require some work, i.e., organizing, to make the situation more sensible so that actions can be interpreted and coordinated. The focus of the present research was to explore how organizing is accomplished through practice and particularly through talk.

There has been some ambiguity in prior theories as to how organizing is related to practice; in particular, how talk is related to actions that are talked about has yet to be clarified. Therefore, it was often implicitly assumed that organizing is done separately from practice. For instance, it can be considered that prior organizing makes practice possible or that practice is 
made sense of only through retrospective narrating. However, if we assume that organizing is done before or after practice and thereby that organizing is separate from the practice, we come to a theoretical dilemma; this being that there needs to be organizing that is external to the practice for the practice to be achieved. The theory of organizing sought to avoid downplaying practice in this way. Practices are neither pre-determined by prior organizing nor undetermined until retrospective organizing. Practices are knowledgeably performed on their own.

The main contribution of this study was to show that organizing is done reflexively; practice requires organizing, but this organizing is reflexively done through the practice itself. The above analysis revealed that this reflexive organizing is done through embedding. Through embedding, different social situations are brought together, yet these situations do not have an explicit and separate narrative. This embedding is rather a subtle process by which objects, people, organizations, and events from different social situations are connected to make the present action sensible. Embedding is related to footing, i.e., how one presents oneself and one's actions. This footing then makes the very action possible by presenting it in the context of a plausible account.

Prior studies have been ambiguous as to how talking is related to an action. Although talking is often seen as an ideational act that is somehow abstract and detached from concrete reality, talking is an action. The analysis in the current study revealed that talking is often problematic and requires organizing. It would be wrong to assume that talking is done separately from an action in order to give sense to the action. The analysis showed that talk organizes itself by means of embedding other social situations. The retrospective narrating that is done separately from actions is itself also an action, and thereby requires separate narration to create sense for it; leading to an infinite regress. Reflexive organizing helps overcome this problem. While retrospective sensemaking, in which actions are narrated after the fact, is clearly important, this does not mean that these actions themselves are senseless. These actions produce organizing as a reflexive part of their own production. 
If we take organizing to be reflexive, then organizing is seen as a pervasive aspect of any organizational life. Organizing is part of any practice; it is not only required for disruptive events in which new order needs to be created. Even seemingly trivial practices, e.g., short moments of talking, require organizing to make them possible. Weick's subtle arguments on organizing and sensemaking touch on seemingly contradictory claims: While he suggests that small talks and short moments matter rather than grandiose events, his theory stresses that organizing starts with interruptions, gaps, differences, arousal, and noticing (Weick, 1995; Weick et al., 2005). The present study's findings clarify and reconcile these two claims further by suggesting that organizing and sensemaking are necessary for all practices, not only salient practices but also routine practices.

In fact, it is critical to note that these practices are not intrinsically routine; rather these practices are made routine through organizing. Through organizing, requesting assistance becomes an easily understandable action and a relevant part of a routine situation. If we only observe routine practices, we may not see the need for organizing of these practices precisely because they are routine. However, we need to inquire how these practices are organized to be routine. For instance, when we use easily deictic terms like "this" and "he," we can do this not because the situation is simply known, but because we embed another social situation to make it known. For this reason, seemingly trivial practices are not without organizing; rather it is organizing that makes the practices seemingly trivial.

\section{Reflexivity in Knowledge Sharing}

The basic question for knowledge sharing is this: How can knowledge sharing be achieved while one is seeking information and therefore lacks complete knowledge of a particular situation? Pre-existing organizations such as roles, rules, social ties, trust relations, tools, and organizational culture are often used to explain how knowledge sharing is achieved. Nonetheless, pre-existing organization does not explain how talk is made possible. We often tend to think that requesting assistance is an easy matter; we merely approach somebody and 
ask a question. Yet, this action is not so simple. In many social situations, one cannot abruptly speak to another person and ask for assistance. We observed that even technicians who share many of the same practices, have strong social ties, and thus constitute a community of practice had difficulty in talking to each other.

The above analysis suggests that practices of knowledge sharing encompass their own organizing in order to create sense. The analysis revealed there is a great amount of work done in talk, e.g., overhearing others' talk and utilizing various objects, people and events, to make the talk possible. Roles, rules and tools are important elements in organizing, but participants need to embed these elements. This embedding is done in talk, not necessarily prior to speaking; we do not need to assume prior organizing that creates a clear sense of the situation.

Furthermore, while scholars have pointed out that people need to tell a coherent story in order to share knowledge, it has remained unclear how participants in an interaction can do so when they do not have sufficient knowledge of a particular situation. The present findings suggest that we do not need to wait for a coherent retrospective narrative to share knowledge. Nor do we need to assume that we must possess a particular level of knowledge about a situation in order to tell a coherent story. The analysis revealed that participants engaged in subtle practices of creating sense for actions of requesting and offering assistance even when these persons did not possess sufficient knowledge of a given situation.

Orr (1996) stressed the mastery required to tell 'war stories.' He, however, viewed that this mastery comes not from the action of telling but from the resulting narrative content in which a problematic situation is handled skillfully: "A coherent diagnostic narrative constitutes a technician's mastery of the problematic situation" (p. 2). In the midst of troubleshooting, technicians have not yet discovered the solution to the problem at hand and cannot exhibit their mastery by telling coherent war stories. Their mastery must lie in how the technicians can accomplish knowledge sharing despite such lack of knowledge.

The framework of embedding suggests two key aspects of this mastery. One is related to production formats and the other to participation frameworks. The notion of production formats 
suggests that when we talk, we do not simply state what we think. We carefully present ourselves by citing somebody else's stories, referencing official organizational arrangements, resuming a story from the past, etc. The interesting finding is that masterful talking is not so much about the competence with which the content is presented as it is related to subtle manners in which various other social situations are embedded. The speakers do not understand the specific situation well enough to fully articulate the story content. Instead, mastery lies in determining what social situation to embed and how.

The notion of participation framework also shows that even when we say the same thing, we can do so in a variety of ways, e.g., talking aloud to oneself and saying something only indirectly. We can enlist various participants who are not officially part of the present circumstances in order to project a certain sense of the situation. Therefore, when we talk, we need to organize by choosing and embedding possible other social situations. Again, this subtle organizing could be as important as the coherent content of the story. If we subscribe to the closed, dyadic model in which somebody speaks and another hears, we cannot explain how knowledge sharing is achieved despite a lack of knowledge. These subtle methods of embedding related to participation frameworks and production formats allow knowledge sharing to be achieved.

These analyses show that the emphasis on 'war stories' (Orr, 1996) is important but limited. Technicians' knowledge sharing is characterized not so much as stories of heroic troubleshooting but are in fact subtle, indirect, and hidden actions that accomplish knowledge sharing despite the speakers lacking the heroic knowledge necessary to tell war stories. Talking is not only situated (Suchman, 1987) but also situating. As Weick $(1979 ; 1995)$ and Czarniawska (1997) suggested, situations are constructed through talking. For instance, when one action is presented as a continuation of an event from a distant past, the situation is constructed so that a meaning of the action is projected. The action of talking therefore situates itself into the current situation by situating this current situation into other social situations. Embedding achieves this complex maneuver in one stroke without explicit explanations. 
Therefore, we need to look for organizing in each instance of talking, rather than in something preexisting or in retrospective narratives.

\section{CONCLUSION}

This study examined how reflexive organizing is done through practice, which is then made possible by the organizing. Empirical cases of knowledge sharing interactions were analyzed in detail. It was shown that service technicians used a verity of methods to organize situations through talk, and in this way the talking is made possible. Goffman's (1981) notion of embedding was useful in explicating the reflexive organizing. Without a clear explanation of this reflexivity, we risk viewing organizing as separate from practice and thereby mystifying organizing as something that somehow makes the practice possible.

To explicate this reflexive organizing, we need to investigate actual actions in detail. In particular, accounts of a particular situation are presented not explicitly in words but by the way in which an action is displayed. The ethnomethodological approach, particularly the conversation analytic method with its use of video recordings, offers much in this regard.

Without examining each action in detail, we can easily overlook the organizing that is critical to make an action possible; instead, we may wrongly conclude that the action is so trivial that no organizing is necessary. We might also erroneously treat the action as unintelligible and relegate its sensemaking to retrospective narrative. By empirically investigating moment-by-moment actions ethnomethodologically, we can minimize these mistakes.

Clearly, more work is necessary if we are to come to a fuller understanding of how the interactions of knowledge sharing are accomplished and more generally how organizing is done reflexively. Although all the practices were identified in this single-case study, more practices might be observed in different settings. Fully specifying the practical methods of knowledge sharing is too complex a topic to fully elucidate in a single study. For instance, we did not observe interactions between strangers, between technicians and their managers, or between functionally different groups. Analyzing such interactions will certainly add to our 
understanding. It is hoped that the findings of this study will prompt future research not only on additional practices, but also on how organizing itself serves as a backdrop for the very process of knowledge sharing.

\section{ACKNOWLEDGMENTS}

I am grateful to Burt Swanson, Barbara Lawrence, Corinne Bendersky, Charles Goodwin, Jack Whalen, Danny Bobrow and many other colleagues for their guidance in this research. I also thank Bill Harley and three anonymous reviewers for their constructive comments and suggestions.

\section{REFERENCES}

Allen, T. J. (1984). Managing the Flow of Technology: Technology Transfer and the Dissemination of Technological Information Within the R\&D Organization. Boston: The MIT Press.

Bittner, E. (1965). 'The concept of organization'. Social Research, 32, 239-255.

Boje, D. M. (1991). 'The storytelling organization: A study of story performance in an officesupply firm'. Administrative Science Quarterly, 36, 106-126.

Boje, D. M. (2001). Narrative Methods for Organizational \& Communication Research. Thousand Oaks: SAGE.

Boje, D. M. (2011). Storytelling and the Future of Organizations. New York: Routledge.

Borgatti, S. and Cross, R. (2003). 'A relational view of information seeking and learning in social networks'. Management Science, 49, 432-445.

Clayman, S. (1993). 'Footing in the achievement of neutrality: The case of news-interview discourse'. In Drew, P. and Heritage, J. (Eds), Talk at Work. Cambridge: Cambridge University Press, 163-198.

Cross, R. (2004). 'Tie and network correlates of individual performance in knowledge-intensive work'. The Academy of Management Journal, 47, 928-937.

Czarniawska, B. (1997). Narrating the Organization. Chicago: University of Chicago Press.

Czarniawska, B. (2008). A Theory of Organizing. Cheltenham, UK: Edward Elgar Publishing.

Davies, B. and Harré, R. (1990). 'Positioning: The discursive production of selves'. Journal for the Theory of Social Behaviour, 20, 43-63.

Edmondson, A. (1999). 'Psychological safety and learning behavior in work teams'. Administrative Science Quarterly, 44, 350-383.

Fox, S. (2008). 'That miracle of familiar organizational things': Social and moral order in the MBA classroom'. Organization Studies, 29, 733-761.

Garfinkel, H. (1967). Studies in Ethnomethodology. Cambridge, UK: Polity.

Garud, R., Dunbar, R. L. M. and Bartel, C. A. (2011). 'Dealing with unusual experiences: A narrative perspective on organizational learning'. Organization Science, 22, 587-601.

Gherardi, S. (2009). Organizational Knowledge. Oxford, UK: Wiley-Blackwell.

Gherardi, S. and Nicolini, D. (2002). 'Learning in a constellation of interconnected practices: Canon or dissonance?'. Journal of Management Studies, 39, 419-436.

Goffman, E. (1981). Forms of Talk. Philadelphia: Univ of Pennsylvania Press.

Hansen, M. (1999). 'The search-transfer problem: The role of weak ties in sharing knowledge across organization subunits'. Administrative Science Quarterly, 44, 82-112. 
Hindmarsh, J. and Llewellyn, N. (2010). 'Finding organisation in detail: Methodological orientations'. In Llewellyn, N. and Hindmarsh, J. (Eds), Organisation, Interaction and Practice. Cambridge: Cambridge University Press, 24-45.

Ibarra, H. and Barbulescu, R. (2010). 'Identity as narrative: Prevalence, effectiveness, and consequences of narrative identity work in macro work role transitions'. Academy of Management Review, 35, 135-154.

Llewellyn, N. and Hindmarsh, J. (Eds.) (2010a). Organisation, Interaction and Practice. Cambridge: Cambridge University Press.

Llewellyn, N. and Hindmarsh, J. (2010b). 'Work and organisation in real time: An introduction'. In Llewellyn, N. and Hindmarsh, J. (Eds), Organisation, Interaction and Practice. Cambridge: Cambridge University Press, 3-23.

Llewellyn, N. and Spence, L. (2009). 'Practice as a members' phenomenon'. Organization Studies, 30, 1419-1439.

Miettinen, R., Samra-Fredericks, D. and Yanow, D. (2010). 'Re-turn to practice: An introductory essay'. Organization Studies, 30, 1309-1327.

Nicolini, D. (2012). Practice Theory, Work, and Organization. Oxford: Oxford University Press.

Orr, J. E. (1995). 'Ethnography and organizational learning: In pursuit of learning at work'. In Organizational Learning and Technological Change. Berlin: Springer, 47-60.

Orr, J. E. (1996). Talking About Machines. Ithaca, NY: Cornell University Press.

Orr, J. E. (2006). 'Ten years of Talking About Machines'. Organization Studies, 27, 1805-1820.

Pentland, B. (1992). 'Organizing moves in software support hot lines'. Administrative Science Quarterly, 37, 527-548.

Pentland, B. T. (1999). 'Building process theory with narrative: From description to explanation'. The Academy of Management Review, 24, 711-724.

Rawls, A. W. (2008). 'Harold Garfinkel, ethnomethodology and workplace studies'. Organization Studies, 29, 701-732.

Reagans, R. and McEvily, B. (2003). 'Network structure and knowledge transfer: The effects of cohesion and range'. Administrative Science Quarterly, 48, 240-267.

Sacks, H., Schegloff, E. A. and Jefferson, G. (1974). 'A simplest systematics for the organization of turn-taking for conversation'. Language, 50, 696-735.

Samra-Fredericks, D. and Bargiela-Chiappini, F. (2008). 'Introduction to the symposium on the foundations of organizing: The contribution from Garfinkel, Goffman and Sacks'. Organization Studies, 29, 653-675.

Schatzki, T. R., Knorr-Cetina, K. and Savigny, von, E. (Eds.) (2001). The Practice Turn in Contemporary Theory. New York: Routledge.

Schegloff, E. A. (2007). Sequence Organization in Interaction: Volume 1: A Primer in Conversation Analysis. New York: Cambridge University Press.

Suchman, L. A. (1987). Plans and Situated Actions: the Problem of Human-Machine Communication. New York: Cambridge University Press.

Tsoukas, H. and Chia, R. (2002). 'On organizational becoming: Rethinking organizational change'. Organization Science, 13, 567-582.

Uzzi, B. and Lancaster, R. (2003). 'Relational embeddedness and learning: The case of bank loan managers and their clients'. Management Science, 49, 383-399.

Weick, K. E. (1979). Social Psychology of Organizing. New York: McGraw-Hill.

Weick, K. E. (1995). Sensemaking in Organizations. Thousand Oaks: Sage Publications, Inc.

Weick, K. E., Sutcliffe, K. M. and Obstfeld, D. (2005). 'Organizing and the process of sensemaking'. Organization Science, 16, 409-421. 


\section{APPENDIX A: CONVERSATION ANALYSIS TRANSCRIPTION SYSTEM}

[ Left square brackets on two successive lines represent the onset of the overlap.

$=\quad$ Equal signs connecting two lines represent no discernible silence between the lines.

(1.2) Numbers in parentheses denote silence in seconds.

(.) A dot in parentheses denotes hearable but not readily measurable short silence.

A period denotes falling intonation, not necessarily the end of a sentence.

, A comma denotes a continuing intonation contour, not necessarily a clause boundary.

? $\quad$ A question mark denotes rising intonation, not necessarily a question.

: $\quad$ Colons denote the prolongation of the sound just preceding them.

word Underlining denotes stress.

$\circ \circ$ The degree signs denote that the talk between them is markedly softer than the talk around it.

- $\quad$ A hyphen denotes a cut-off.

$>\quad$ Inwards arrowheads denote that the talk between then is rushed.

(word) Parentheses around a word or a phrase denote the transcriber's guess at what might be said.

$\mathrm{h} \quad$ The letter ' $\mathrm{h}$ ' denotes exhaling.

.h The letter ' $h$ ' preceded by a period denotes inhaling.

[word] Square brackets denote the author's substitution to disguise names. 
Table I: Summary of the Data

\begin{tabular}{|c|c|c|c|c|c|c|c|}
\hline $\begin{array}{r}\text { Techni } \\
\text { cians } \\
\end{array}$ & Area & $\begin{array}{l}\text { Years in } \\
\text { service }\end{array}$ & $\begin{array}{c}\text { Product } \\
\text { specialization }^{a}\end{array}$ & $\begin{array}{l}\text { Number } \\
\text { of calls }\end{array}$ & $\begin{array}{c}\text { Hours of } \\
\text { observation }\end{array}$ & $\begin{array}{l}\text { Minutes of } \\
\text { video data }\end{array}$ & $\begin{array}{c}\text { Hours on } \\
\text { service calls }\end{array}$ \\
\hline Tom & $\begin{array}{l}\text { San Jose } \\
\text { San }\end{array}$ & 17 & Color & 3 & 9.33 & 153.8 & 5.17 \\
\hline Tony & Francisco & 26 & MV & 4 & 6.27 & 144.7 & 2.23 \\
\hline Tim & Sacramento & 17 & $\mathrm{HV}$ & 4 & 8.08 & 123.3 & 6.04 \\
\hline Tiffany & Oakland & 16 & MV & 2 & 4.00 & 62.4 & 2.13 \\
\hline Trent & Oakland & 13 & MV & 1 & 3.25 & 120.1 & 1.98 \\
\hline Ted & San Jose & 13 & MV & 1 & 3.67 & 105.3 & 1.42 \\
\hline Titus & Concord & 17 & Color & 3 & 8.17 & 295.6 & 5.20 \\
\hline Tristan & Sacramento & $0.33^{b}$ & Color & 3 & 6.75 & 179.4 & 3.10 \\
\hline Todd & Pleasanton & 30 & $\mathrm{HV}$ & 1 & 4.08 & 101.2 & 1.15 \\
\hline Tanner & $\begin{array}{l}\text { San Jose } \\
\text { San }\end{array}$ & 31 & $\mathrm{HV}$ & 2 & 6.08 & 162.3 & 1.25 \\
\hline Tate & Francisco & 24 & $\mathrm{HV}$ & 3 & 8.25 & 265.0 & 4.33 \\
\hline Trinity & Sacramento & 16 & $\mathrm{HV}$ & 5 & 6.58 & 194.8 & 3.30 \\
\hline Travis & Marin & 18 & $\mathrm{HV}$ & 4 & 6.92 & 98.4 & 2.40 \\
\hline Trevor & San Mateo & 6 & MV & 3 & 6.58 & 155.6 & 2.47 \\
\hline Taylor & Stockton & 9 & G & 7 & 9.42 & 335.2 & 3.78 \\
\hline \multirow[t]{3}{*}{ Terry } & San Jose & 17 & Color & 2 & 8.50 & 406.6 & 5.12 \\
\hline & & & Total & 48 & 105.9 & 2904.0 & 51.1 \\
\hline & & & Mean & 3 & 6.6 & 181.5 & 3.2 \\
\hline
\end{tabular}

${ }^{\mathrm{a}}$ Color $=$ color products, $\mathrm{MV}=$ midvolume, $\mathrm{HV}=$ high-volume, $\mathrm{G}=$ generalist

${ }^{\mathrm{b}}$ This technician had been in another technical job for six years before he was transferred to this job. 